\title{
A SIMPLE MODEL FOR FLOW ON HILLSLOPES
}

\author{
T.S. Steenhuis ${ }^{1}$, J.Y. Parlange ${ }^{1}$, M.B. Parlange ${ }^{2}$ and F. Stagnitti ${ }^{3}$ \\ 1 Department of Agricultural Engineering, Cornel1 University, Ithaca, \\ NY 14853, U.S.A. \\ 2 Department of Civil and Environmental Engineering, Corne11 University, \\ Ithaca, NY 14853, U.S.A. \\ 3 Mathematics Department, Warrnambool Institute for Advanced Education, \\ P.0. Box 423, Warrnambool, Victoria 3280, Australia
}

\section{ABSTRACT}

A simple hillslope hydrological model predicting water movement on sloping shallow soils is developed. Unlike existing hillslope models, the new model can be used to predict flow for long records of climatological data and it can be easily extended to include preferential flow. It compares favorably to other models with more restrictive input requirements. Its application is illustrated for experimental data collected for an homogeneous hillslope at the Cooweeta Hydrological Laboratory.

\section{INTRODUCTION}

Hillslopes in forest and nature reservations have an interconnecting network of macropores, animal burrows and other pores which can conduct large amounts of water. For this reason the Hortonian surface runoff mechanism (i.e. runoff occurs when the rainfall intensity exceeds the infiltration capacity of the soil surface) has seldom been observed (Hewlett and Hibbert, 1965; Dunne, 1983; Ward, 1984).

Subsurface flow, especially piping, quick return flow or interflow, is particularly significant in undisturbed forest watersheds as a source of water for streams (Corbett, 1979). The surface organic matter maintains high surface permeabilities (not allowing surface crusting by rain drop impact) and the upper soil profile contains numerous pathways for rapid water flow. If an impermeable layer is reached by percolating water, water moves downhill towards the hillslope bottom. There are also many other observations of preferential flow on hillslopes (Whipkey, 1965; Retezer, 1963; Hewlett and Hibbert, 1965; Dunne and Black, 1970; and last but not least Lawles et al., 1882).

Various algorithms, ranging from simple analytical models to complex finite element models which may include macropore flow, have been developed for describing the saturated/unsaturated flow on hillslopes. Analytical models were developed by Stagnitti et al., (1986) and Hurley and Pantelis (1985). These do not include a mechanism to assess the effect of macropores and only can be carried out for one storm at a time. Finite difference and finite element models developed by Nieber and Walter (1981), Nieber (1982), Beven (1981), Sloan and Moore (1984) in theory can be run for an infinite time but the practicality of computer time and cost usually reduces their applicability to a storm period.

The purpose of this paper is to present an alternative hydrologic model which, unlike others, can determine the drainage and moisture 
distribution profiles throughout the year and is valid for soils with macropores. It is a simple budget routine, that can be run as part of a spreadsheet program such as $1-2-3$.

The paper is divided in several parts. In the first part a finite difference scheme is developed for the interflow and surface runoff when the moisture content of the soil is above field capacity. In the second part the processes are addressed when the moisture content is below field capacity, the interflow is small and the evaporation fluxes are most important. (The definition of field capacity for the purpose of this paper is the moisture content below which the downhill fluxes are negligible.) In the third part a modified Thornthwaite Mather procedure is used to evaluate evapotranspiration and interflow for hillslopes. Finally, the fourth part addresses the accuracy of the model.

\section{MOISTURE CONTENT ABOVE FIELD CAPACITY}

In a shallow soil layer overlaying an impermeable bed, soilwater diffusion tends to maintain a uniform moisture content over the depth of the soil. Therefore, the volumetric moisture content, $\theta$, can be assumed to be uniform at a given elevation (Stagnitti et al., 1986, 1987) or, as Hurley and Pantelis (1985) showed, the total potential is uniform perpendicular to the slope. In both cases, the variation of $\theta$ with time $t$, is primarily dependent on the downhill flux $q$, which is controlled by the hillslope angle, $\beta$, and the soil water hydraulic conductivity $K(\theta)$. Under these simplifying conditions, the equation governing the subsurface flow of water is given by (Stagnitti et a1., 1986):

$$
\frac{\partial m}{\partial t}+\frac{\partial q}{\partial x}=(P-E) / D
$$

where (P-E)/D is a source sink term representing the difference between average precipitation $P$, and evapotranspiration $E$, per unit volume of soil. $D$ is the average depth to the impermeable layer. In the case that the width, $y$, slope, $\beta$, and depth to the impermeable layer, $z$ vary moderately in the downslope direction, the average volumetric water content, $m$ and the average flux per unit area, $q$, should be used and equal:

$$
\begin{aligned}
& \mathrm{m}=\iint \theta d y d z / \iint d y d z \\
& \mathrm{q}=\iint k(\theta) * \sin (\beta) d y d z / \iint d y d z=a k(m)
\end{aligned}
$$

where the variable "a" can be a function of $x$ which is of the order of $\sin \beta$. The space coordinate $x$ is directed down the slope, $x=0$ is located at the hilltop and $x=L$ is located at the outflow point, (gauge house or stream channe1). In this form the equations are similar to those currently used in describing overland flow and they can be solved by the same methods. Combining equations 1 and 3 and using the chain rule for $k(m)$ gives

$$
\frac{\partial m}{\partial t}+a \frac{d k(m)}{d m} \frac{\partial m}{\partial x}=\frac{P-E}{D}
$$


where the dependence of $a$ on $x$ has been neglected for simplicity. The characteristics of equation 4 are obtained by solving the following ordinary differential equations:

$$
\frac{\mathrm{dt}}{1}=\frac{\mathrm{dx}}{\mathrm{adk}(\mathrm{m}) / \mathrm{dm}}=\frac{\mathrm{dm}}{(\mathrm{P}-\mathrm{E}) / \mathrm{D}}
$$

The left hand and middle term of equation 5 imply that the characteristic velocity equals:

$$
\mathrm{v}=\frac{\mathrm{dx}}{\mathrm{dt}}=\mathbf{a d k}(\mathrm{m}) / \mathrm{dm}
$$

The right-hand side of equation 5 suggests that:

$$
\frac{\mathrm{dm}}{\mathrm{dt}}=\frac{\mathrm{P}-\mathrm{E}}{\mathrm{D}}
$$

so that, along the characteristic defined by (6), m increases with the precipitation excess. Since the terms $a$ and $(P-E) / D$ are assumed here to be independent of space and as long as the term $\mathrm{dk}(\mathrm{m}) / \mathrm{dm}$ is independent of moisture content (i.e., the conductivity is a linear function of the moisture content) then integration of equations 6 and 7 give respectively,

$$
\begin{aligned}
& x-a \frac{d k(m)}{d m}\left(t-t_{0}\right)=x_{t_{0}} \\
& m-\int_{t_{0}}^{t} \frac{P-E}{D} d \bar{t}=F\left(x_{t_{0}}\right)
\end{aligned}
$$

where the constant $x_{t_{0}}$ is the position of a point at time $t_{0}$ and $F\left(x_{t_{0}}\right)$ is an unknown function of $x_{t_{0}}$.

\section{Finding the Moisture Content}

For $x_{t_{0}} \geq 0$ and $t=t_{0}$, we find from equation 9 that the constant $F\left(x_{t_{0}}\right)$ is equal to the moisture content $m\left[x_{t_{0}}, t_{0}\right]$ along the slope at time $t_{0}, v i z$

$$
m[x, t]-\int_{t_{0}}^{t} \frac{P-E}{D} d \bar{t}=m\left[x_{t_{0}}, t_{0}\right]
$$

Using the following two relationships:

$$
t-\Delta=t_{0}
$$

and

$$
x-\Delta x=x_{t_{0}}
$$


equation 10 may be written in finite difference form at a time $(t+\Delta)$ as:

$$
m[x, t+\Delta t]=m[x-\Delta x, t]+I
$$

where $\Delta x$ and $\Delta t$ are related according to equation 6 or

$$
\Delta \mathrm{x}=\mathrm{a} \Delta \mathrm{t} \mathrm{dk}[\mathrm{m}] / \mathrm{dm}=\mathrm{v} \Delta \mathrm{t}
$$

and

$$
I=\int_{t}^{t+\Delta t} \frac{P-E}{D} d \bar{t}
$$

Thus, the moisture content may be found by taking the moisture content at previous time step at a distance $\Delta x$ uphill while accounting for the net gain or loss due to precipitation and evaporation. This moisture content moves downhill at velocity $v$.

Equation 13 is identical with the expression in Stagnitti and Parlange (1987) and it is almost the same as the differential equations of Stagnitti et a1. (1986) except for the addition of the source sink term. The problem with the finite difference formulation in equation 13 is that the derivative of the conductivity function with respect to the moisture content has to be constant, i.e., the conductivity has to be a linear function of the moisture content. A more realistic result with the same advantage of fixed gridpoints in time and space may be obtained by introducing a piecewise linear conductivity function (Fig. 1):

$$
\begin{array}{ll}
k_{j}(m)=K_{j-1}+\left(K_{j}-K_{j-1}\right) \frac{m-M_{j-1}}{M_{j}-M_{j-1}} & \text { for } M_{j-1}<m \leq M_{j} \\
& j=1,2, \ldots, n \\
k_{0}(m)=0 & \text { for } 0<m \leq M_{0}
\end{array}
$$

where $j$ varies from 1 to $n$

$M_{j}$ is the upper limiting moisture content of a piecewise linear approximation to the conductivity function

$\mathrm{K}_{\mathrm{j}}$ is the upper conductivity value of the piecewise approximation

$\mathrm{K}_{\mathrm{n}}$ is the saturated hydraulic conductivity, $\mathrm{k}_{\mathrm{S}}$, and

$M_{n}$ is the saturated moisture content, $\theta_{s}$

The moisture content, $m[x, t+\Delta t]$, can then be found, (similarly to equation 13), by summing the contribution over each piecewise linear portion of the unsaturated conductivity function. Thus by dividing the total moisture content, $m$, in portions $\Delta \mathrm{m}_{i}$ we find for the moisture content and flux for a particular location $x$ at time $t+\Delta t$, respectively:

$$
m[x, t+\Delta t]=\sum_{i=1}^{n} \Delta m_{i}\left[x-\Delta x_{i}, t\right]+M_{0}+I
$$




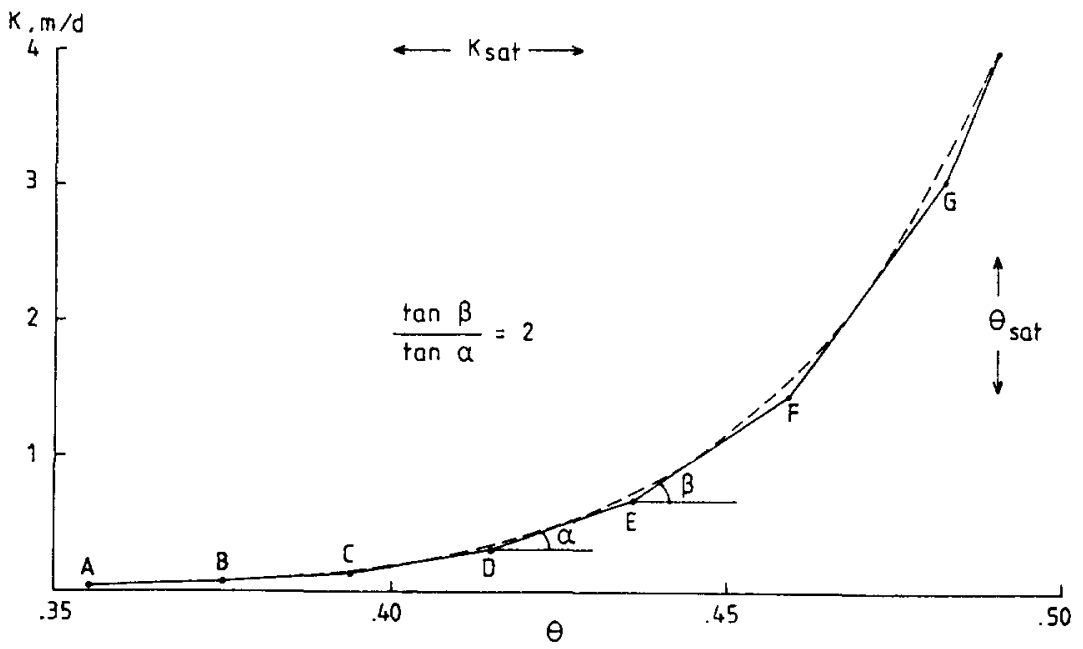

Fig. 1. Approximation of $K(\theta)$ by a piecewise linear function.

where

$$
\begin{array}{ll}
\Delta m_{i}\left[x-\Delta x_{i}, t\right]=M_{i}-M_{i-1} & \text { when } M_{i}<m\left[x-\Delta x_{i}, t\right] \\
\Delta m_{i}\left[x-\Delta x_{i}, t\right]=m\left[x-\Delta x_{i}, t\right]-M_{i-1} & \text { when } M_{i-1}<m\left[x-\Delta x_{i}, t\right] \leq M_{i}
\end{array}
$$

and

$$
\Delta m_{i}\left[x-\Delta x_{i}, t\right]=0 \quad \text { when } m\left[x-\Delta x_{i}, t\right] \leq M_{i-1}
$$

and analogous to equation 14 the distance upstream $\Delta x_{i}$ becomes:

$$
\Delta x_{i}=v_{i} \Delta t
$$

where the characteristic velocity equals:

$$
\begin{array}{ll}
v_{i}=a \frac{\left(K_{i}-K_{i-1}\right)}{M_{i}-M_{i-1}} & \text { for } M_{i-1}<m \leq M_{i} \\
v_{0}=0 & \text { for } m \leq M_{0}
\end{array}
$$




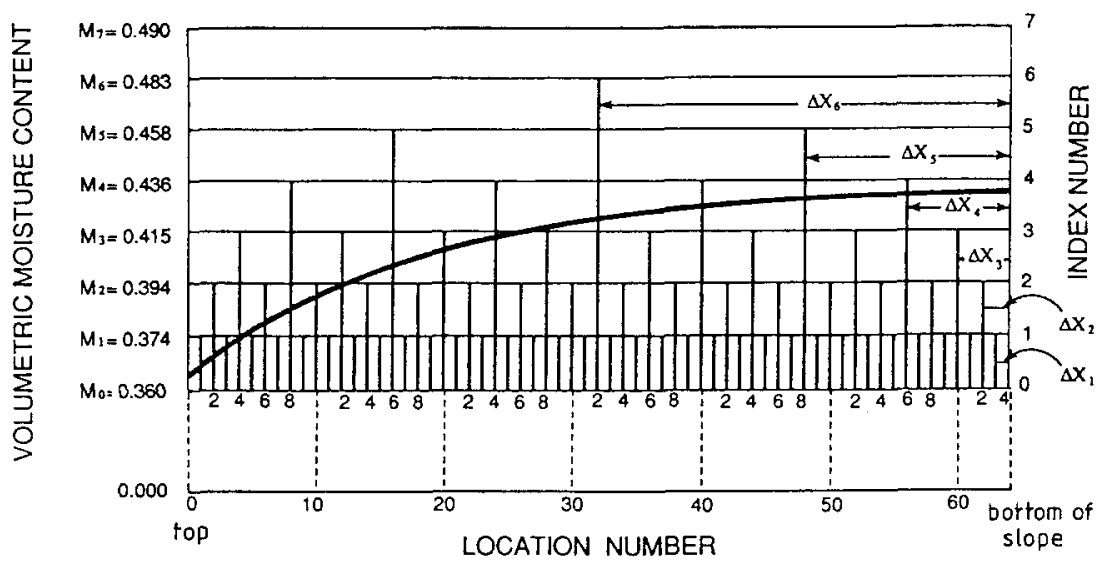

Fig. 2. Schematic representation of hillslope with steady state irrigation. The solid curved line is the moisture content profile. The horizontal lines represent the limiting moisture contents of the piecewise linear conductivity function and the vertical lines represents the corresponding distances over which the water moves in $\Delta t$ minutes. For choice of $M_{1}$-values see text.

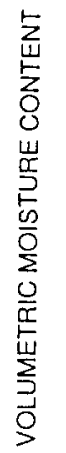

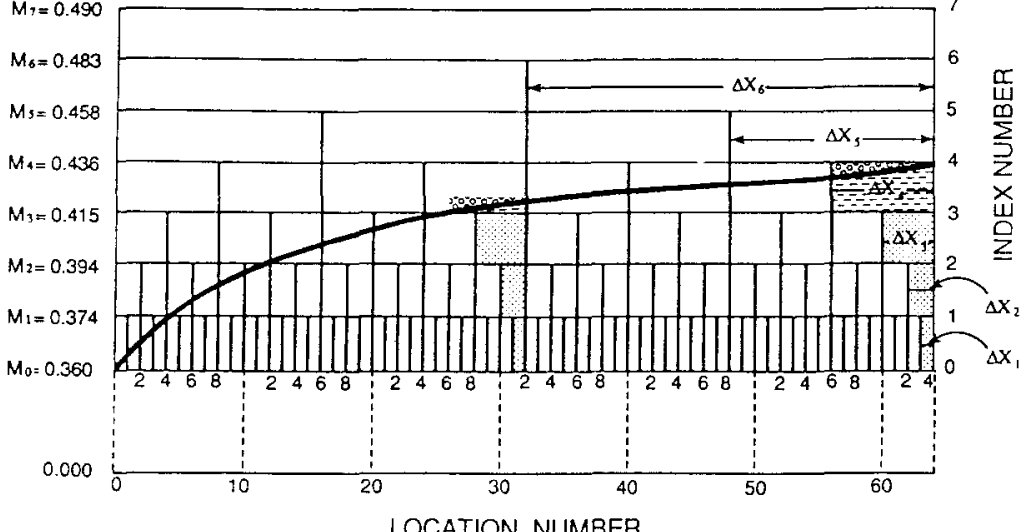

LOCATION NUMBER

Fig. 3. Schematic representation of hillslope with steady state irrigation. The shaded areas represents the runoff at location 64 and 32 in a time interval from $t$ to $(t+\Delta t)$. 
Fig. 2 is used to demonstrate the above equations. The situation depicted shows the top of the hillslope with a steady state irrigation. The resulting moisture content is depicted by the dark solid line. The linear sections of the $K(M)$ Relation are chosen in such a way that the slope of each section is twice that of its predecessor (Fig. 1). Therefore the distances, $\Delta \mathrm{x}_{\mathbf{i}}$, between the vertical lines are determined such that in equation 23:

$$
v_{i-1}=\frac{1}{2} v_{i}
$$

and consequently

$$
\Delta x_{i-1}=\frac{1}{2} \Delta x_{i} \quad \text { or } \quad \Delta x_{i}=2^{(i-1)} \Delta x_{i}
$$

The $\mathrm{x}$ axis is divided in units of $\Delta \mathrm{x}_{1}$ the left-hand side at $\mathrm{x}=0$ being the top of the hill. The solid horizontal lines are the moisture contents $M_{i}$ in between which the conductivity is linear; these values are chosen such that equation 25 is obeyed. Thus the moisture contents at field capacity, $M_{0}=0.36$ and $M_{1}=0.374$ represent the limiting moisture contents for the lowest linear approximation to the unsaturated conductivity function with a slope of $v_{1} / a$ (the associated distance is $\Delta x_{1}$, whereas the nest section has a double slope.

For example to determine the moisture content at time $t+\Delta t$ at location 64 equations 18 through 21 are used. Thus to find the moisture content at $x$ at time $t+\Delta t, m[x, t+\Delta t]$, all contributions of $\Delta m_{i}\left[x-\Delta x_{i}, t\right]$ where $i$ goes from 1 to 7 , are sumned. Starting with $i=1$, the moisture content at distance $\Delta x_{1}$ upstream (i.e., location 63) is compared with the limiting moisture content $M_{1}$. As can be seen from Fig. 2 the limiting moisture content, $M_{1}$, is smaller than the moisture content $m\left[x-\Delta x_{1} t\right]$ or $m[63, t]$. Thus from equation 19 :

$$
\Delta \mathrm{m}_{1}=M_{1}-M_{0}=0.374-0.36=0.014
$$

Next $i=2$ is considered and the moisture content at location 62 is compared with the limiting moisture content $M_{2}$. Again we observe that the moisture content at location 62 is higher than the appropriate limiting moisture content $M_{2}$. For $i=3$ the situation is analogous. For $i=4$, the moisture content at location 56 ( 8 units $\Delta x_{1}$ ) is examined. Fig. 2 shows that the moisture content is between $M_{3}$ and $M_{4}$. Thus, equation 20 is applied to determine the $\Delta \mathrm{m}_{4}\left[x-\Delta x_{4}, t\right]$. Notice, that in contrast to location 64 , the $\Delta m_{4}\left[x-\Delta x_{4}, t\right]$ at location 32 is 0 . For $i=5,6$ and 7 the condition in equation 21 is met. Consequently, when $i$ is larger than or equal to five, $\Delta \mathrm{m}_{i}\left[\mathrm{x}-\Delta \mathrm{x}_{i}, t\right]$ is equal to zero.

The expression for moisture content in equation 18 may be simplified, using the definitions in equations 19 through 21 . Call $\mathrm{j}$ the maximum value for $i$ for which

$$
m\left[x-\Delta x_{i}, t\right]>M_{i-1} \text { and } x-\Delta x_{i} \geq 0
$$

For the case that the moisture content at $\left(x-\Delta x_{j}\right)$ satisfies

$$
M_{j-1}<m\left[x-\Delta x_{j}, t\right] \leq M_{j}
$$


equation 18 becomes:

$$
m[x, t+\Delta t]=m\left[x-\Delta x_{j}, t\right]+I
$$

In the other case that

$$
m\left[x-\Delta x_{j}, t\right] \geq M_{j}
$$

equation 18 may be replaced by

$$
m[x, t+\Delta t]=M_{j}+I
$$

In Fig. 2 at location 64 the value for $j=4$ ad the condition stated in equation 29 is fulfilled. For location $32, j=3$ and the condition in equation 32 is valid.

\section{Finding the Flux}

In general the total amount of water passing location $x$ from a time $t$ to $(t+\Delta t)$, is called $Q[x, t+\Delta t]$ and can be found as :

$$
Q[x, t+\Delta t]=\int_{t}^{t / \Delta t} q d t^{\prime}
$$

For a piecewise linear conductivity function defined in equation 16 the amount of water that may be attributed to the flux in the range from $M_{i-1}$ to $M_{i}$ over a time period of $\Delta t$ is named $Q_{i}[x, t+\Delta t]$ and the total flux is expressed as:

$$
Q[x, t+\Delta t]=\sum_{i=1}^{n} Q_{i}[x, t+\Delta t] \int_{t}^{t+\Delta t} q_{i} d t=\sum_{i=1}^{n} \bar{q}_{i} \Delta t
$$

where $\overline{q_{i}}$ is the average flux at location $x$ over the time period $\Delta t$ attributed to the water flow in the range of moisture content from $M_{i-1}$ and $M_{i}$. Associated with the $\bar{q}_{i}$ is a velocity of water, $v_{i}$, and a $\Delta m_{i}[x, t]$ (similarly defined as in equations 19,20 and 21 , but at location $x$ instead of a $\left.-\Delta \mathbf{x}_{i}\right)$.

$$
Q_{i}[x, t+\Delta t]=\overline{q_{i}} \Delta t=\overline{\Delta m_{i}} v_{i} \Delta t=\overline{\Delta m_{i}} \Delta x_{i}
$$

where $\overline{\Delta m}_{1}$ is the average value of $\Delta m_{i}$ at location $x$ over time period of $\Delta t$. Inspection of Fig. 2 shows that

$$
\overline{\Delta m}_{i}[x, t+\Delta t]=M_{i}-M_{i-1} \quad \text { when } M_{i} \leq m[x-\Delta x, t]
$$


Thus the time averaged flux becomes

$Q_{i}[x, t+\Delta t]=\overline{q_{i}} \Delta t=\left(M_{i}-M_{i-1}\right) \Delta x_{i}$ when $M_{i} \leq m\left[x-\Delta x_{i}, t\right]$

If $h$ is the maximum value for $i$ for which

$M_{i} \leq m\left[x-\Delta x_{i}, t\right]$

then for the case that $m[x, t]>M_{h}$, the excess $\left(m-M_{h}\right)$ integrated between $\left(x-\Delta x_{h+1}\right)$ and $x$ will cross the point $x$ to which the second order correction, $\frac{1}{2} I$, has been added. Thus:

$$
Q_{h+1}[x, t+\Delta t]=\int_{x-\Delta x_{h+1}}^{x}\left\{m[x, t]-M_{h}+\frac{1}{2} I\right\} d x
$$

When on the interval from $\left(x-\Delta x_{h+1}\right)$ to $\left(x-\frac{1}{2} x_{h+1}\right)$ the moisture content falls below $M_{h}$, this water will travel at lower velocity and has to be excluded from the term to be integrated. With this condition the total flux at point $x$ can written as

$$
Q[x, t+\Delta t]=\sum_{i=1}^{h}\left(M_{i}-M_{i-1}\right) \Delta x_{i}+\int_{x-\Delta x}^{x}\left\{m(x, t)-M_{h}+\frac{1}{2} I\right\} d x
$$

where $h$ is defined in equation 38 and $\Delta x$ is the lesser of $\Delta x_{h+1}$ and the distance between $x$ and the point where the moisture content becomes smaller than $\mathrm{M}_{\mathrm{h}}$.

In Fig. 3 the amount of flux at locations 32 and 64 is depicted. The different shades represent the various terms in equation 40 . Note that for both locations $h$ equals 3 . However at location $32\left(\mathrm{~m}[\mathrm{x}, \mathrm{t}]-M_{h}\right)$ is not greater than 0 over the whole range of $\Delta x_{4}$.

\section{Boundary Conditions}

At $x=0$ there is a Neumann boundary condition (i.e., influx is known). When the uphill node is the highest point of the hillside then the influx is zero. The condition is fulfilled if the water content at $x<0$ is taken at field capacity at all times for computational purposes.

Another condition is that the moisture content cannot exceed the saturated moisture content. Consequent1y, all precipitation in excess of the saturated soil becomes runoff and is assumed to reach the point $x=L$ instantly.

\section{Finite Difference Formulation for Computer Application}

For computer application a regular spaced grid is needed. This is accomplished by using the provision stated in equations 25 and 26 . Using a distance of $\Delta x_{1}$ (the smallest grid size) between the nodes equation 30 may be written in the more conventional finite difference form 


$$
m_{k}^{t+1}=m_{k-p}^{t}+I
$$

where the superscript refers to the time and the subscript refers to the location of the node. The subscript p equals

$$
p=\frac{\Delta x_{j}}{\Delta x_{1}}=2(j-1)
$$

An iterative process is required to find the p. Starting at the lower end of the hillslope $k=s$ (where $s=L / \Delta x_{1}$ ) and going uphill (i.e., lowering $k$ by 1 ) an initial value for $p$ is estimated corresponding to the moisture content of node $k$ at time $t$ (i.e., $m_{k}^{t}$ ). If the moisture content at node $k-p$, $m_{k-p}^{t}$, is smaller than $M_{j-1}$ the value of $p$ is divided by 2 (or $j_{t}$ is reduced by 1 ) and the procedure is repeated until $M_{j-1}$ is less than $m_{k-p}^{t}$. Then similarly to equation 32 if $m_{k-p}^{t}$ is less or equal to $M_{j}, m_{k-p}^{t}$ is replaced by $M_{j}$ in equation 41. This approach is allowed because the soil is always dryer when going uphill.

The flux may be found at any node $k$, based on equation 40 as:

$$
Q_{k}^{t+1}=\Delta x_{1}\left[\sum_{i+1}^{h}\left\{2^{(i-1)}\left(M_{i}-M_{i-1}\right)\right\}+\sum_{\tau=1}^{s}\left(m_{k-\tau}^{t}-M_{h}+\frac{1}{2} I\right)\right]
$$

where $s$ is the lesser of $2^{h}$ and the number of nodes for which $\left(m_{k-\tau}^{t}-M\right)>0$

The Neumann boundary condition at $x=0$ is most easily simulated by adding a number of mirror nodes uphill with a moisture content equal to field capacity as already mentioned.

The runoff condition is simulated by adding up all moisture in excess to the saturated moisture content at the end of the time step. Note, that when runoff occurs, $\frac{1}{2} I s \Delta x_{1}$ must be removed from the source sink term to conserve mass.

\section{BELOW FIELD CAPACITY}

Below field capacity the water change is entirely due to evaporative fluxes. The Thornthwaite Mather procedure (Thornthwaite and Mather, 1955, 1957; Steenhuis and Van der Molen, 1986) can be used in this situation. Because the moisture content increases downslope, the T-M procedure needs, therefore, to be carried out for each node.

The method of calculating the moisture content depends on whether the potential evaporation is larger or smaller than the precipttation per time period.

When the potential evaporation is larger or smaller than the precipitation, the moisture content can be found with the following two equations (Steenhuis and Van der Molen, 1986): 


$$
\begin{aligned}
& A_{k}^{t+1}=A_{k}^{t}-I \\
& m_{k}^{t+1}=m_{w p}+\left(m_{f c}-m_{w p}\right)\left(\exp \frac{A_{k}^{t+1}}{m_{f c}-m_{w p}}\right.
\end{aligned}
$$

where $m_{f c}=M_{0}$ is the moisture content at field capacity, $m_{w p}$ is the moisture content at wilting point and $A$ is the accumulated potential water loss per unit volume of root zone soil. A is zero when the moisture content is equal to field capacity. Equations 44 and 45 are based on a linear dependency of actual evaporation and moisture content between field capacity and wilting point.

In case the precipitation is larger than the potential evaporation, then the moisture content in the soil is incremented by the net amount of infiltration, viz:

$$
m_{k}^{t+1}=m_{k}^{t}+I
$$

The cumulative water loss for the next time step, $A_{k}^{t+1}$, is calculated with equation 45 .

GENERAL PROCEDURE (OR THE THORNTHWAITE MATHER PROCEDURE ADAPTED FOR HILLSLOPES)

We have now developed two sets of equations when the moisture content is above field capacity and when it is below field capacity. The equations below field capacity are essentially the same as in the original 1955 paper. The equations above field capacity have an additional term from water coming in from the upper slope. Also the outflow is directed along the slope instead of vertically downward.

Consequently by using equations 41 and 42 for each node for above field capacity and 44,45 and 46 for drier conditions, a modified general procedure for hillslopes is formed. It has as said before much of the same characteristics as the Thornthwaite Mather procedure to calculate streamflow. How the procedure is exactly carried out, is demonstrated with an example.

\section{An Example}

The hillslope experiment described by Hewlett (1961) and Hewlett and Hibbert (1963) is used here to illustrate use of the parameters in equations above. In this experiment a steady state irrigation was applied at a rate, estimated by Stagnitti et al (1986) of $0.0606 \mathrm{~m} /$ day. After the irrigation was turned off the outflow was measured. The plot's width and the depth to the impermeable layer was $0.92 \mathrm{~m}$, the length $=13.72 \mathrm{~m}$ and $\mathrm{sin} \beta$ $=0.37$. Sloan and Moore (1984) in their simulation employed a Brooks and Corey type of conductivity function: 
$k(\theta)=k_{s}\left[\frac{\theta-\theta_{d}}{\theta_{s}-\theta_{d}}\right]^{1 / n}$

with values for the saturated conductivity $K_{s}=4.032 \mathrm{~m} /$ day, a value for $1 / \mathrm{n}=14.63, \theta_{\mathrm{s}}=0.49$ and $\theta_{\mathrm{d}}=0.0$.

The first step in solving the problem is defining the grid in time and space, which can be accomplished by using equations 22 and 23 . Unlike other finite difference schemes there is a relationship between the distance between the nodes $\Delta x_{1}$, the time increment $\Delta t$ and the field capacity $M_{O}$ (i.e., two degrees of freedom and three variables).

Dividing the hillside into 256 nodes gives a distance between the grid points of $0.054 \mathrm{~m}$, which seems to be reasonable. Two different time steps are required to solve efficiently the problem. The reason being that the experiment was run for over 50 days, while the initial time that the runoff is recorded is only $100 \mathrm{~min}$. Thus, using a value for $\Delta t$ of 100 minutes ( 0.069 days) results in a value for $v_{1}$ of 0.776 . Using $\sin \beta=0.37$ the value of the tangent to the conductivity curve becomes 2.09 .

Using the value of 2.09 for the slope of the first line tangent to the unsaturated curve defined in equation 16 , the remaining coordinates may be found by intersecting the lines with twice the slope and which are tangent the conductivity function (Fig. 1). The results are shown below in table 1 . The moisture content at field capacity $M_{O}$ is equal to 0.36 .

Table 1. Values used for Piecewise linear conductivity function

\begin{tabular}{llllllllll}
\hline$j$ & 7 & 6 & 5 & 4 & 3 & 2 & 1 & 0 \\
$\mathrm{M}_{\mathrm{j}}$ & 0.4900 & 0.4829 & 0.4589 & 0.4362 & 0.4145 & 0.3940 & 0.3744 & 0.3559 \\
$\mathrm{~K}_{\mathrm{j}}$ & 4.032 & 3.0512 & 1.4499 & 0.6890 & 0.3274 & 0.1556 & 0.0739 & 0.0351 \\
$\mathrm{slope}$ & 133.7600 & 66.8800 & 33.4400 & 16.7200 & 8.3600 & 4.1800 & 2.0900 \\
\hline
\end{tabular}

For a time step of 0.25 days we find for a spacing of $0.054 \mathrm{~m}$ a value for $\left(a v_{1}\right)=0.054$ and $v_{1}=0.146$. The moisture content at field capacity is 0.32 . Having two different field capacities might seem strange on first sight. However, this is a direct result of how small "negligible" fluxes are in the definition of field capacity. Under actual field conditions this also has been observed: an irrigated field has a higher field capacity than the same field under dry land agriculture (Gardner, 1975, personal communications).

The distribution of moisture content at the time when the rainfall stopped, was obtained by running the model with constant precipitation until steady state outflow was obtained.

The cumulative drainage for this simple computer model is plotted in Fig. 4 along with the simplified drainage model of Stagnitti et al., 1986, Sloan and Moore's kinematic storage model, Hewlett and Hibbert's experiment and Nieber's finite element solution. Our computer model obviously is in good agreement with the other models. This is no surprise as they are all an approximation to Richards equation. 


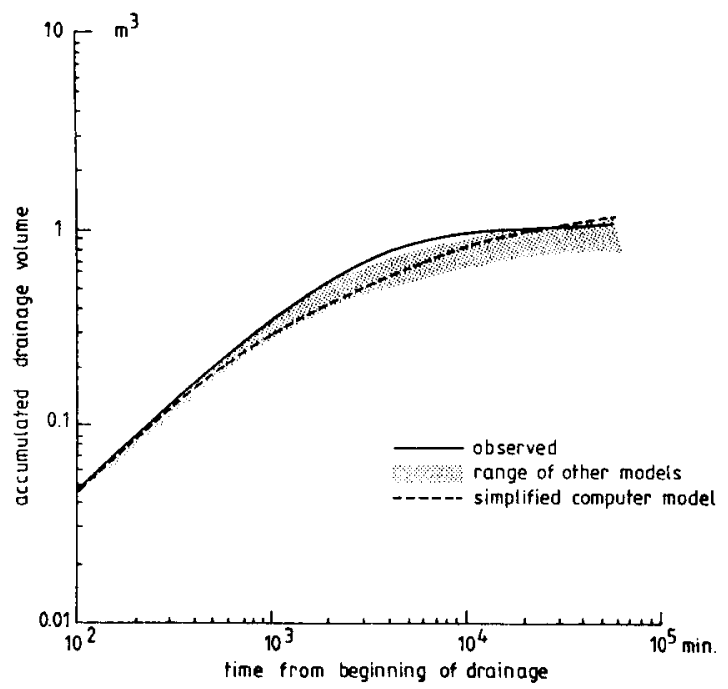

Fig. 4. Comparison between observed and predicted cumulative runoff curves. The shaded area represents the outside boundaries of the predictions for Nieber's two dimensional finite element solution, the kinematic storage model proposed by Sloan and Moore and the simplified drainage equation of stagnitti et al. (Figure is adapted from Stagnitti et al., 1986).

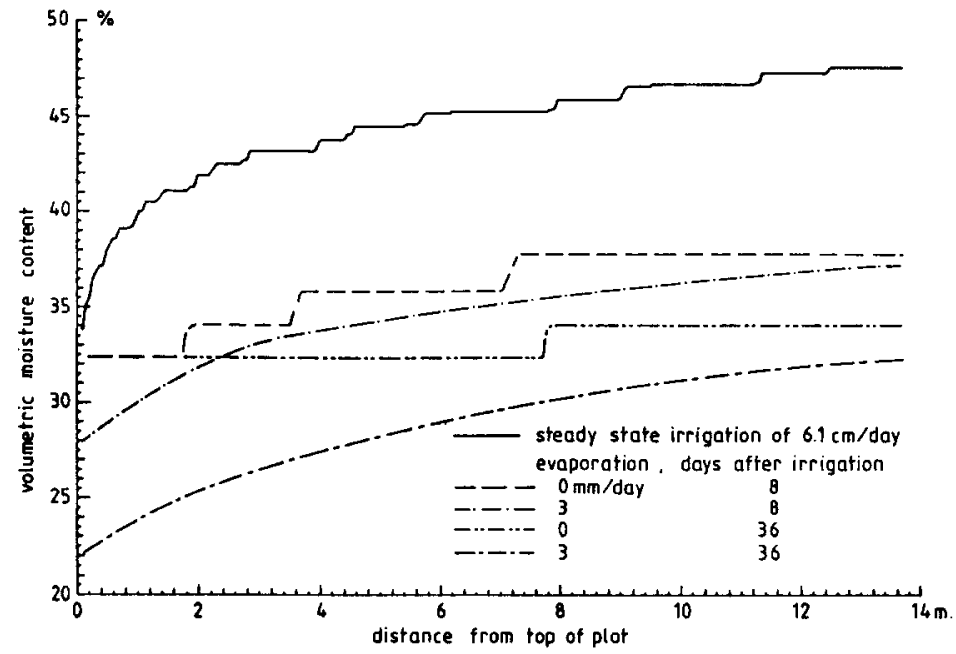

Fig. 5. Moisture content distribution for the Hewlett and Hibbert experiment with and without evaporation at 0,8 and 36 days after the irrigation was stopped. 
In Fig. 5 the moisture content at different times is plotted for the Hewlett and Hibbert experiment with no evaporation and with a potential evaporation of $3 \mathrm{~mm} /$ day. The moisture profiles are depicted for the steady state profile and 8 and 36 days after the irrigation has stopped. Note that the evaporation makes the water content vary more continuously than without evaporation. It is also clear that unless the soil is very wet the evaporation is an extremely important parameter. This is also observed in New York: as soon as the grass becomes green the small creeks stop flowing.

\section{APPLICATION TO PREFERENTIAL SOLUTE FLOW}

The procedures developed so far give the same characteristics for homogeneous and non-homogeneous soils. The preferential flow paths, as always, have a more direct influence on the solute flow. Two limiting cases are considered.

$$
S[x, t+\Delta t]=\sum_{i=1}^{n} \Delta m_{i}\left[x-\Delta x_{i}, t\right] * C\left[x-\Delta x_{i}, t\right]
$$

and

$$
\begin{aligned}
& S_{i}[x, t+\Delta t]=\Delta m_{i}\left[x-\Delta x_{i}, t\right] * C_{i}\left[x-\Delta x_{i}, t\right] \\
& S[x, t+\Delta t]=\sum_{i=1}^{n} S_{i}[x, t+\Delta t]
\end{aligned}
$$

where $S$ is the solute amount per unit area. Thus the solute at any location depends on the amount brought in from different distances $\Delta x_{i}$, which is the definition of preferential flow. Equation 48 represents the mixed flow model while equation 49 and 50 are without any intermixing between the different flow paths. Thus in the fully mixed model there is a concentration $C$ at a given $x$, whereas $C_{i}$ in equation 46 represents the concentration in the pores corresponding to a water content between $M_{i}$ and $M_{i-1}$. In a subsequent paper we will test which of the two models is most appropriate for describing the solute flow on a hillslope and for what soil and climatic conditions and add the evaporative effects on solute concentrations which are neglected in equations 48-50.

\section{CONCLUSION}

The simplified finite difference hillslope model has been demonstrated to be a good approximation of Richards equation. The model gives reliable prediction of drainage from an homogeneous soil segment. It has the potential for predicting preferential flow on non-homogeneous hillslopes. This last case has not been fully tested yet.

The distinct advantage that the simple finite difference model exhibits over the other hillslope models is that it can be used for predicting moisture content profiles and drainage outflow over long records of historical climatological data. 
The implementation on the computer is relatively simple and the input data requirements are minimal. It has therefore the potential for inclusion into existing models used for predicting watershed response.

\section{REFERENCES}

Beven, K.J., 1981. Kinematic subsurface stormflow. Water Resources Research $17(5): 1419-1424$.

Corbett, E.S., 1979. Hydrological evaluation of the stormflow generation process on a forested watershed. Ph.D. Thesis. Office of Water Res. and Techn. Washington, DC. NTIS.

Dunne, T. and R.D. Black, 1970. An experimental investigation of runoff production in permeable soils. Water Resources Research 6(2):478-490.

Dunne, T., 1983. Relation of field studies and modeling in the prediction of storm runoff, J. Hydrol., 65, 25-48.

Hewlett, J.D. and A.R. Hibbert., 1965. Factors affecting the response of small watersheds to precipitation in humid areas. In: Forest Hydrology, New York. pp. 275-290.

Hewlett, J.D., 1961. Soil moisture as a source of base flow from steep mountain waterheds, USDA For. Serv. Res. Pap. SE, 132, 1-10.

Hurley, D,G. and G. Pantelis, 1985. Unsaturated and saturated flow through a thin porous layer on a hillslope. Water Resources Research $21: 821-824$.

Lawes, J.B., J.H. Gilbert and R. Warington, 1882. On the amount and composition of the rain and drainage water collected at Rothamstead. Williams Glowes and Sons, Ltd., London.

Nieber, J.L. and M.F. Walter., 1981. Two-dimensional soil moisture flow in a sloping rectangular region: experimental and numerical studies. Water Resources Research 17(6):1722-1730.

Nieber, J.L., 1982. Hillslope soil moisture flow, approximation by a onedimensional formulation. Paper 82-2026. American Society of Agricultural Engineers, St. Joseph, MI. $28 \mathrm{pp}$.

Retezer, J.L., 1963. Soil formation and classification of forested mountain lands in the United States. Soil Science 96(1):68-74.

Sloan, P.G. and I.D. Moore, 1984. Modeling surface and subsurface stormflow on steeply sloping forested watersheds. Water Resources Research $20(12): 1815-1822$.

Stagnitti, F., M.B. Parlange, T.S. Steenhuis and J.-Y. Parlange, 1986. Drainage from a uniform soil layer on a hillslope. Water Resources Research 22(5):631-634.

Stagnitti, F. and Parlange, J.-Y 1987. Streamflow generation from variable width, inclined, shallow hillslopes. The Institution of Engineers Australia, Mechanical Engineering Transactions, Me12:86-92.

Stagnitti, F., Parlange, M.B. Steenhuis, T.S. and Parlange, J.-Y., 1987. Reply to comment by D.G. Hurley and G. Pantelis. Water Resources Research. In press.

Steenhuis, T.S. and Van der Molen, W.H., 1986. The Thornthwaite-Mather procedure as a simple engineering method to predict recharge. J. Hydrology, 84:221-229.

Thornthwaite, C.W. and Mather, J.R., 1955. The water balance. Publ.Climatol., $8(1)$. 
Thornthwaite, C.W. and Mather, J.R.,, 1957. Instructions and tables for computing potential evapotranspiration and the water balance. Publ. Climatol., 10(3).

Ward, R.C., 1984. On the response to precipitation of headwater streams in humid areas, J. Hydrol., 74, 171-189.

Whipkey, R.Z., 1965. Subsurface stormflow on forested slopes. Bul1. Inter-national Assoc. Sci. Hydrology 10(2):74-85. 